\title{
SUBSTÂNCIAS HÚMICAS AQUÁTICAS: FRACIONAMENTO MOLECULAR E CARACTERIZAÇÃO DE REARRANJOS INTERNOS APÓS COMPLEXAÇÃO COM ÍONS METÁLICOS
}

\author{
Ézio Sargentini Junior \\ Instituto Nacional de Pesquisas da Amazônia (INPA), CP 478, 69083-000 Manaus - AM \\ Julio Cesar Rocha*, André Henrique Rosa, Luiz Fabricio Zara \\ Instituto de Química de Araraquara-UNESP, CP 355, 14800-900 Araraquara - SP \\ Ademir dos Santos \\ Instituto de Química de São Carlos - USP, CP 780, 13561-140 São Carlos - SP
}

Recebido em 9/6/00; aceito em 13/9/00

\begin{abstract}
AQUATIC HUMIC SUBSTANCES: MOLECULAR SIZE FRACTIONATION AND CHARACTERIZATION OF INNER REARRANGEMENTS AFTER METAL IONS COMPLEXATION. The aquatic humic substances (AHS) investigated in this study were conventionally isolated from Rio Negro waters - Amazonas State/ Brazil by means of the collector XAD 8. A special five-stage tangential-flow ultrafiltration device was used for analytical fractionation of AHS. The fractionation patterns ( 6 fractions each) showed that metal traces remaining in AHS after their XAD 8 isolation have different size distributions. For instance, the major percentage of traces of $\mathrm{Ni}, \mathrm{Cu}, \mathrm{Zn}, \mathrm{Cd}$ and $\mathrm{Pb}$ (determined using ICP-AES) was preferably complexed by molecules with relatively high molecular size (30-100 kDa) and the following complexation order was characterized: $F_{2} \gg F_{1}=F_{4}=F_{5}>F_{3}>F_{6}$. Moreover, the species formed between AHS and metals prepared by spiking, showed distribution patterns changing as a function of the complexation time (ageing process), indicating a slow transformation process and an inner rearrangements in the binding sites within the AHS molecules.
\end{abstract}

Keywords: aquatic humic substances; fractionation; metal ions.

\section{INTRODUÇÃO}

Substâncias húmicas (SH) são formadas pela transformação de biomoléculas, durante o processo de decomposição de resíduos vegetais e animais presentes no ambiente. Devido a natureza heterogênea e complexa das $\mathrm{SH}$, pouco se sabe sobre sua estrutura química e apresentam-se como misturas heterogêneas de moléculas polidispersas com elevada massa molar ${ }^{1,2}$. Possuem alto teor de grupos funcionais contendo oxigênio na forma de carboxilas, hidroxilas fenólicas e carbonilas. Devido suas características estruturais as $\mathrm{SH}$ podem interagir com metais e compostos orgânicos como por exemplo, pesticidas e herbicidas presentes no ambiente. Para compreender o comportamento das SH no ambiente, estas têm sido estudadas sob diferentes aspectos: caracterização de estruturas parciais, determinação de constantes de equilíbrio de espécies metal-SH, acidez ${ }^{3}$, labilidade relativa de metais, etc. ${ }^{4}$.

A definição de substâncias húmicas aquáticas (SHA) está baseada em métodos cromatográficos de extração. Thurman \& Malcolm ${ }^{5}$ definiram SHA como a porção não específica, amorfa, constituída de carbono orgânico dissolvido (COD) em pH 2 e adsorvente em coluna de resina XAD 8, não iônica, com altos valores de coeficiente de distribuição. A fração extraída de COD em uma amostra depende do tipo de resina utilizada, da quantidade de amostra e do eluente utilizado. Consequentemente, amostras extraídas por métodos diferentes geralmente não são comparáveis. Ainda, de acordo com Thurman \& Malcolm ${ }^{5}$ e Senesi ${ }^{6}$, SHA compreendem cerca de um terço até a metade do COD na água e são constituídas em sua maior parte por ácidos hidrofóbicos. Estes, podem apresentar concentração de $20 \mu \mathrm{g} \mathrm{L}^{-1}$ em águas de subsolo, chegando a $30 \mathrm{mg} / \mathrm{L}$ em águas de superfície ${ }^{7}$. Grande parte do COD em sistemas aquáticos tropicais com coloração escura, por exemplo o Rio Negro - AM - Brasil, apresenta-se como substâncias húmicas aquáticas ${ }^{8,9}$.

A Amazônia Central é região de topografia essencialmente plana com menos de 40 metros de declividade de Manaus-AM até o oceano Atlântico. Tem rios de tamanhos variados e igarapés (riachos) contribuindo para a formação das bacias dos dois grandes rios do centro da Amazônia, o Solimões e o Negro, os quais encontram-se nas proximidades de Manaus ${ }^{10}$. O Rio Negro é um dos maiores afluentes do Rio Amazonas. De acordo com Ertel ${ }^{11}$, é responsável pela maior parte do fluxo de ácidos húmicos para o Rio Amazonas, contribuindo com cerca de 2,5 vezes mais que o Rio Solimões. As substâncias húmicas do Rio Negro chegam à água por drenagem dos solos arenosos das campinas. Os igarapés que fazem essa drenagem tornam-se pretos e as SH são responsáveis pela permanência do $\mathrm{pH}$ desses igarapés entre 3,5 - 3,9. Durante prolongados períodos secos, não ocorre percolação e os igarapés transportam somente águas e íons estocados por muito tempo no solo argiloso, aumentando a alcalinidade, o teor iônico e diminuindo a coloração das águas. Entretanto, $\log$ o com as primeiras chuvas, as águas tornam-se novamente escuras e ácidas ${ }^{10}$.

A contribuição do presente trabalho foi caracterizar a distribuição de níquel, cobre, zinco, cádmio e chumbo em frações com diferentes tamanhos moleculares de substâncias húmicas extraídas de amostras de água do Rio Negro. Além disto, obtiveram-se importantes informações a respeito da ocorrência de rearranjos inter e/ou intramoleculares, quando as macromoléculas húmicas interagem com íons metálicos em sistemas aquáticos.

\section{EXPERIMENTAL}

\section{Amostragens}

O sítio de amostragem fica à margem esquerda do Rio Negro-AM, entre as confluências dos Rios Tarumã Mirim e Tarumã Açu, a cerca de $20 \mathrm{~km}$ a oeste da cidade de ManausAM, Figura 1.

O nível mais baixo da água ocorre entre novembro e dezembro e o mais alto entre junho e julho. Com o período de 


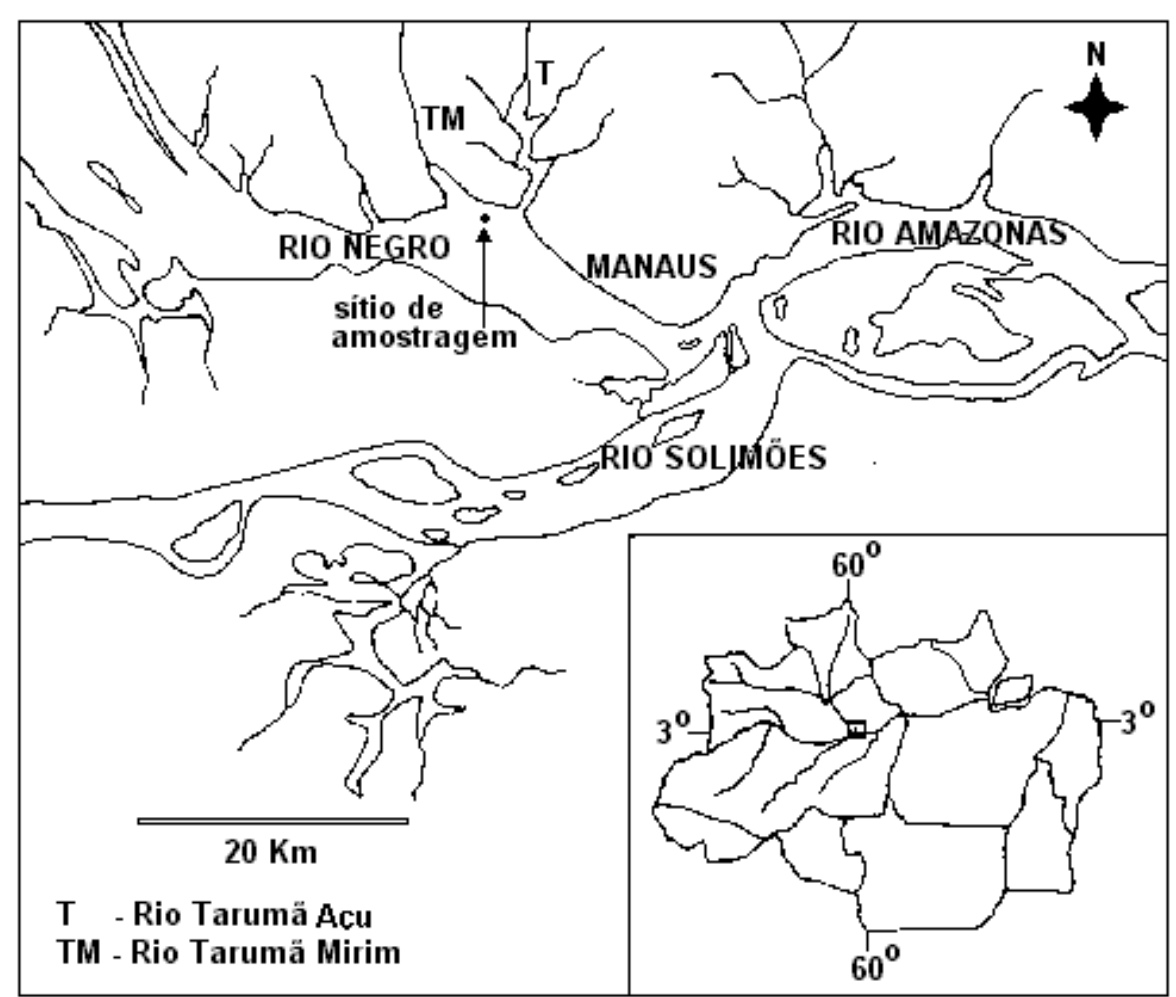

Figura 1. Sítio de amostragens de água do Rio Negro - AM, entre as confluências dos Rios Tarumã Mirim e Tarumã Açu.

enchente as águas do Rio Negro alagam as florestas, várzeas e igarapés. A partir de junho inicia-se a vazante retirando as águas da floresta e no período da seca, entre setembro e janeiro, os igarapés permanecem em seus pequenos canais. As coletas foram feitas nos períodos entre fevereiro e setembro de 1998 coletando-se 8 amostras (100 litros cada) à $50 \mathrm{~cm}$ da superfície ${ }^{12}$.

\section{Extrações das substâncias húmicas aquáticas com resina XAD 8}

A resina macroporosa XAD 8 utilizada para a extração de SHA foi previamente purificada por bateladas sucessivas com soluções de ácido clorídrico $0,50 \mathrm{~mol} \mathrm{~L}^{-1}$, hidróxido de sódio $0,50 \mathrm{~mol} \mathrm{L^{-1 }}$ e metanol, respectivamente ( 24 horas cada batelada). Para extração, utilizou-se procedimento recomendado pela International Humic Substances Society (IHSS) ${ }^{13}$. As amostras foram filtradas em sistema de filtração a vácuo com papel de filtro Whatman $42 \mathrm{e}$, em seguida, acidificadas com solução de ácido clorídrico $6,0 \mathrm{~mol} \mathrm{~L}^{-1}$ até pH 3,0. Então, por gravidade, percolaram-se, as amostras através de colunas de vidro ( $2 \mathrm{~cm}$ de diâmetro interno e $25 \mathrm{~cm}$ de altura) empacotadas com resina XAD 8 , com fluxo de $4 \mathrm{~mL} \mathrm{~min}^{-1}$. Após saturação, verificada pelo escurecimento da resina, percolaram-se $10 \mathrm{~mL}$ de solução de ácido clorídrico $0,01 \mathrm{~mol} \mathrm{~L}^{-1}$ para a remoção de impurezas e fez-se eluição com solução de hidróxido de sódio $0,10 \mathrm{~mol} \mathrm{~L}^{-1}$, com vazão de $1,2 \mathrm{~mL} \mathrm{~min}^{-1}$. Após a primeira eluição purificou-se a resina e colocaram-se as colunas novamente em operação.

Para maior representatividade, misturaram-se os extratos obtidos das 8 amostras coletadas em diferentes datas e ajustouse o pH do extrato húmico final em 5,0 ( $\mathrm{pH}$ original das amostras de água do Rio Negro) com solução de ácido clorídrico $0,10 \mathrm{~mol} \mathrm{~L}^{-1}$.

\section{Purificação dos extratos húmicos}

Antes do fracionamento das substâncias húmicas aquáticas, fez-se diálise para remoção do excesso de sais dissolvidos.
Prepararam-se as membranas de diálise (Samless cell 16 X 100 clear) segundo o procedimento descrito por Town et al. ${ }^{14}$. Após tratamento por 10 minutos com solução de bicarbonato de sódio $2 \%(\mathrm{~m} / \mathrm{v})$ e solução de EDTA dissódico dihidratado $0,01 \mathrm{~mol} \mathrm{~L}^{-1}$, lavaram-se as membranas com água desionizada $\left(65^{\circ} \mathrm{C}\right)$ e estocou-se em refrigerador.

$\mathrm{O}$ extrato húmico foi concentrado em evaporador rotativo e purificado utilizando-se membrana de diálise contra água deionizada até teste negativo para cloretos (teste com solução de nitrato de prata $\left.0,10 \mathrm{~mol} \mathrm{~L}^{-1}\right)^{15}$. Após a remoção do excesso de sais dissolvidos por diálise, liofilizou-se o extrato húmico conforme procedimento descrito por Pitombo ${ }^{16}$ e estocou-se o material em pesa filtro mantido em dessecador.

\section{Caracterizações}

\section{Análise elementar}

Determinou-se a composição elementar das SHA em relação ao conteúdo de carbono, hidrogênio, oxigênio, nitrogênio e enxofre em equipamento para análise elementar CHNSO CE Instruments, Perkin Elmer, EA 1110.

\section{Teor de matéria orgânica e inorgânica}

Transferiu-se 0,5000 $\mathrm{g}$ das SHA extraídas para cadinho previamente tarado e calcinou-se em mufla a $750{ }^{\circ} \mathrm{C}$ por 4 horas. Calculou-se o teor de matéria orgânica pela diferença de massa após calcinação, considerando-se o resíduo final como matéria inorgânica ${ }^{17}$.

\section{Capacidade de complexação e carbono orgânico dissolvido}

Determinou-se a capacidade de complexação das SHA por potenciometria, utilizando-se eletrodo íon seletivo de cobre como descrito por ROCHA et al. ${ }^{18}$. A concentração de carbono orgânico dissolvido (COD) da amostra filtrada e nas 
frações foi determinada pelo método de combustão catalítica sob atmosfera de oxigênio e subsequente detecção em equipamento Analyser Schimadzu TOC 2000.

\section{Tempo de complexação metal-SHA}

Em $1000 \mathrm{~mL}$ de solução de SHA 1,0 mg mL $\mathrm{mL}^{-1}$ adicionaramse soluções de $\mathrm{Ni}, \mathrm{Cu}, \mathrm{Zn}, \mathrm{Cd}$ e $\mathrm{Pb}$ em volumes adequados para obter solução final com $0,5,0,25,10,0,0,25$ e $2,5 \mathrm{mg} \mathrm{L}^{-1}$ de cada metal, respectivamente. Deixou-se sob agitação mecânica durante dez dias mantendo-se o pH em 5,0. Nas primeiras 24 horas e após 10 dias, retiraram-se alíquotas de $250 \mathrm{~mL}$ para posterior fracionamento.

\section{Fracionamento das SHA utilizando ultrafiltração sequencial em múltiplos estágios e fluxo tangencial - SFSUF}

O fracionamento das SHA foi feito utilizando o sistema desenvolvido recentemente por Rocha et al. ${ }^{19}$. Para tal, bombearam-se $250 \mathrm{~mL}$ de SHA $\left(1,0 \mathrm{mg} \mathrm{mL}^{-1}, \mathrm{pH} 5,0\right)$ através do sistema SFSUF, obtendo-se as seguintes frações com diferentes tamanhos moleculares: $\mathrm{F}_{1}:>100, \mathrm{~F}_{2}: 50-100, \mathrm{~F}_{3}: 30-50, \mathrm{~F}_{4}$ : 10-30, $\mathrm{F}_{5}: 5-10$ e $\mathrm{F}_{6}:<5$ kDalton.

\section{Digestão dos extratos húmicos}

Transferiram-se alíquotas de $10 \mathrm{~mL}$ do extrato húmico para frascos de $50 \mathrm{~mL}$ e secou-se em estufa de circulação forçada a $55{ }^{\circ} \mathrm{C}$. Após secagem, no mesmo frasco, adicionou-se $1,0 \mathrm{~mL}$ de solução de ácido nítrico concentrado pré-purificado utilizando-se destilador construído em quartzo ("subboiling"), 1,0 $\mathrm{mL}$ de solução de peróxido de hidrogênio $30 \%(\mathrm{v} / \mathrm{v})$, cobriuse com vidro de relógio e aqueceu-se em chapa até a solução tornar-se límpida. Transferiu-se o digerido para balão volumétrico de $25,00 \mathrm{~mL}$ e completou-se o volume com água. Quando necessário, repetiu-se adição de ácido nítrico / peróxido de hidrogênio nas mesmas quantidades.

\section{Determinações de metais por ICP-AES}

Determinaram-se a concentração de níquel, cobre, zinco, cádmio e chumbo por espectrometria de emissão atômica com plasma de argônio induzido ICP-AES, utilizando-se soluções padrão mistas para construção da curva de calibração e as seguintes condições operacionais: detecção simultânea (CID, "change-injection device"); leitura em axial; nebulizador concêntrico: 32 psi; câmara de nebulização: 30 psi; nebulização e refrigeração com argônio; aspiração: $2,4 \mathrm{~mL}$ min $^{-1}$; fluxo de gás auxiliar: $0,50 \mathrm{~L} \mathrm{~min}{ }^{-1}$; rádio frequência: $1550 \mathrm{~W}$ (fixa); tempo de integração: $20 \mathrm{~s}$; linhas de emissão: Ni 221,647 \{116\} [II]; Cu 327,396 \{079\} [I]; Zn 213,856 \{121\} [I]; Cd 228,802 $\{113\}[\mathrm{I}]$ e $\mathrm{Pb} 261,418\{100\}[\mathrm{I}]$.

\section{RESULTADOS E DISCUSSÃO}

A Tabela 1 lista informações gerais sobre a amostra de água coletada no Rio Negro-AM.

\section{Análise elementar \\ Embora bastante utilizada para caracterização de substâncias húmicas, a análise elementar é uma técnica limitada quanto a informações sobre a estrutura das SH. É um recurso auxiliar o qual permite comparações entre classes e origens de diferentes materiais húmicos, é útil para avaliar a eficiência dos procedi- mentos de extração e purificação ${ }^{20}$ e para estimativa do conteú- do de grupos funcionais oxigenados. Estes grupos são tidos como responsáveis pelas interações das $\mathrm{SH}$ com compostos}

orgânicos e inorgânicos, por exemplo, íons metálicos ${ }^{1,2}$. Os valores encontrados para o teor de cinzas, composição elementar e razões $\mathrm{H} / \mathrm{C}$ e C/N, nas SHA, bem como dados citados na literatura encontram-se listados na Tabela 2.

De acordo com os dados da Tabela 2, os valores encontrados para composição elementar das SHA extraídas de água do Rio Negro-AM estão próximos aos citados por Leenheer ${ }^{21}$, o qual também trabalhou com SHA extraídas de amostras de água coletadas no Rio Negro-AM. As razões molares H/C e C/N fornecem indicativos sobre estruturas e formas moleculares das substâncias húmicas ${ }^{22}$. O conteúdo de hidrogênio está relacionado com o grau de saturação, isto é, um aumento no teor de hidrogênio indica maior número de carbonos alifáticos $\left(\mathrm{CH}_{2}\right)$ que carbonos aromáticos $(\mathrm{C}=\mathrm{C})^{23}$. A razão molar $\mathrm{H} / \mathrm{C}$ calculada para SHA $(1,70: 1)$, indica carbonos de caráter mais alifáticos em comparação com os dados de Leenheer ${ }^{21}$. Também, a comparação das razões $\mathrm{C} / \mathrm{N}$, infere um menor grau de humificação das amostras de SHA utilizadas no presente estudo.

Tabela 1. Informações gerais e algumas características físicoquímicas da amostra de água coletada no Rio Negro-AM, entre fevereiro a setembro de 1998.

\begin{tabular}{ll}
\hline Parâmetros determinados & Resultados \\
\hline $\mathrm{pH}$ & 5,0 \\
Condutividade & $7-9 \mu \mathrm{S} \mathrm{cm}$ \\
Temperatura & $29-32{ }^{\circ} \mathrm{C}$ \\
Cor & $90 \mathrm{uH}$ \\
Turbidez & $18,0 \mathrm{FTU}$ \\
$\mathrm{COD}$ & $12 \mathrm{mg} \mathrm{C} \mathrm{L}^{-1}$ \\
$\mathrm{Capacidade} \mathrm{de} \mathrm{complexação}$ & $2,8{\mathrm{mmol} \mathrm{Cu}(\mathrm{II}) \mathrm{gCOD}^{-1}}_{\mathrm{Ni}}$ \\
$\mathrm{Cu}$ & $33,5 \mu \mathrm{g} \mathrm{L}^{-1}$ \\
$\mathrm{Zn}$ & $38,5 \mu \mathrm{g} \mathrm{L}^{-1}$ \\
$\mathrm{Cd}$ & $70 \mu \mathrm{g} \mathrm{L}^{-1}$ \\
$\mathrm{~Pb}$ & $<0,1 \mu \mathrm{g} \mathrm{L}^{-1}$ \\
\hline
\end{tabular}

Tabela 2. Composição elementar, teor de cinzas, razões H/C e $\mathrm{C} / \mathrm{N}$ de substâncias húmicas aquáticas extraídas de amostras de água do Rio Negro-AM.

\begin{tabular}{|c|c|c|c|c|c|c|c|}
\hline \multicolumn{8}{|c|}{ Composição Elementar } \\
\hline Amostra & & & 6) & & & & \\
\hline & $\mathrm{C}$ & $\mathrm{H}$ & $\mathrm{O}$ & $\mathrm{N}$ & Cinzas & $\mathrm{H} / \mathrm{C}$ & $\mathrm{C} / \mathrm{N}$ \\
\hline SHA RN & 39,6 & 5,6 & 52,9 & 1,8 & 34,9 & $1,70: 1$ & $25,6: 1$ \\
\hline SHA RN $\mathrm{RN}^{\mathrm{a}}$ & 47,9 & 4,7 & 45,0 & 1,7 & 28,5 & $1,18: 1$ & $33,3: 1$ \\
\hline
\end{tabular}

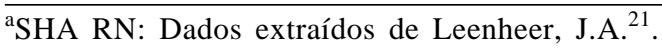

\section{Influência do tempo de complexação metal-SHA}

A grande variedade de tamanho molecular, característica das substâncias húmicas aquáticas, deveria em princípio, permitir a separação da amostra em muitas frações específicas. Devido as complexas associações intermoleculares, na prática, é difícil obter frações com tamanhos moleculares específicos. Entretanto, mesmo tratando-se de intervalos de tamanhos moleculares, o fracionamento é um importante procedimento para melhor compreender o comportamento das substâncias húmicas no ambiente ${ }^{24}$.

A Figura 2a mostra a distribuição das frações de SHA com diferentes tamanhos moleculares em função das respectivas porcentagens de carbono e de íons metálicos originalmente complexados. Observa-se que a fração de menor tamanho molecular $\mathrm{F}_{6}(<5 \mathrm{kDa})$ tem cerca de quatro vezes mais carbono que a fração de maior tamanho molecular $F_{1}(>100 \mathrm{kDa})$ 
e as frações de tamanhos moleculares intermediários têm entre 10-20\% de carbono. Assim, após o fracionamento, pode-se estabelecer a seguinte ordem decrescente de distribuição de carbono nas diferentes frações: $\mathrm{F}_{6}>\mathrm{F}_{2}>\mathrm{F}_{3}>\mathrm{F}_{5}=\mathrm{F}_{4}>\mathrm{F}_{1}$. A perda no balanço de massa, cerca de $2-8 \%$, é atribuída à adsorção de matéria orgânica na superfície das membranas do sistema de ultrafiltração ${ }^{25}$. Burba et al. ${ }^{25}$ e Rocha et al. ${ }^{18}$ estudando SHA do Rio Rhur-Alemanha (extraída por ultrafiltração) e SHA do Rio Negro AM-Brasil (extraída com resina XAD 8), respectivamente, observaram uma distribuição com a maioria da massa de SHA concentrada nas frações de tamanhos moleculares médios $F_{2}(50-100 \mathrm{kDa})$ e $\mathrm{F}_{3}(10-50 \mathrm{kDa})$. Entretanto, as condições experimentais utilizadas por esses autores não foram as mesmas deste trabalho e portanto, os dados não são comparáveis.
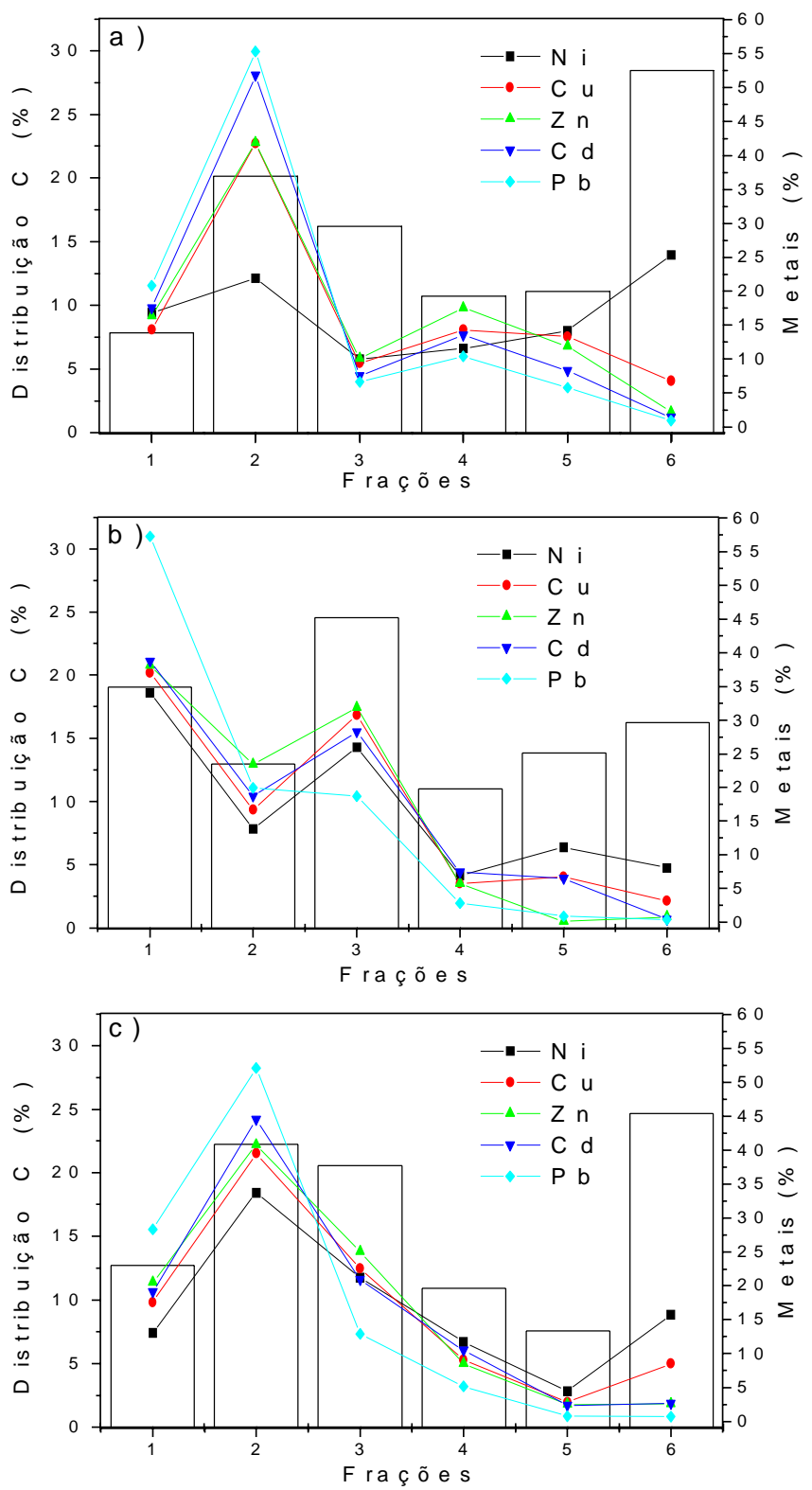

Figura 2. Distribuição de frações de substâncias húmicas aquáticas extraídas de amostras de água do Rio Negro-AM, em função do tamanho molecular e concentrações de espécies metálicas: a) originalmente complexadas (SHA); b) após adição de íons metálicos com tempos de complexação de 24 horas (metal-SHA 1D); c) após 10 dias de complexação (metal-SHA 10D). Condições: $250 \mathrm{~mL}$ SHA 1,0 mg $L^{-1}$ mantida em pH 5,0; adição de Ni 0,50; Cu 0,25, Zn 10,0; Cd

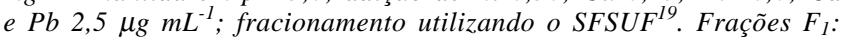
$>100, F_{2}:$ 50-100, $F_{3}$ : 30-50, $F_{4}:$ 10-30, $F_{5}:$ 5-10 e $F_{6}:<5$ kDa.
A Figura $2 \mathrm{~b}$ mostra que após adição de íons metálicos, durante as primeiras 24 horas de contato (metal-SHA 1D), a distribuição de carbono modificou para todas as frações em comparação com as frações SHA, Figura 2a (sem adição de metais). Neste caso, caracterizou-se a seguinte ordem intermediária de distribuição de carbono nas diferentes frações: $F_{3}>$ $F_{1}>F_{6}>F_{5}=F_{2}>F_{4}$. Entretanto, após 10 dias de contato entre as substâncias húmicas e os íons metálicos, metal-SHA $10 \mathrm{D}$, Figura 2c, caracterizou-se uma ordem decrescente de distribuição de carbono nas frações de diferentes tamanhos moleculares semelhante àquela estabelecida para a SHA sem adição de metais, Figura 2a, ou seja: $\mathrm{F}_{6}>\mathrm{F}_{2}>\mathrm{F}_{3}>\mathrm{F}_{1}>\mathrm{F}_{4}$ $>\mathrm{F}_{5}$. Estes resultados reforçam a hipótese da ocorrência de rearranjos inter e/ou intramoleculares nas macromoléculas húmicas quando estas interagem com íons metálicos formando diferentes espécies metal-SHA ${ }^{26,27 .}$

A distribuição de metais em águas naturais possibilita um melhor entendimento dos fenômenos de transporte, acumulação e biodisponibilidade das várias espécies metálicas no ambiente aquático. Além da determinação das concentrações de SH nas frações com diferentes tamanhos moleculares, o fracionamento das amostras possibilita, também, avaliar a distribuição de espécies metal-SHA inertes em meio ácido, e ainda retidas nas SHA após a extração com resina XAD 8 de amostras de água acidificadas a $\mathrm{pH} 3,0$. Nesse trabalho optouse por estudar a distribuição de $\mathrm{Ni}, \mathrm{Cu}, \mathrm{Zn}, \mathrm{Cd}$ e $\mathrm{Pb}$ pois, estes elementos têm características reconhecidamente relevantes quando se trata de impactos ambientais causados por excessivo aporte de metais pesados em recursos hídricos.

A Figura 2a mostra que a maior porcentagem dos íons metálicos originalmente presentes nas SHA está complexada na fração $F_{2}(50-100 \mathrm{kDa})$. Nas demais frações a porcentagem de distribuição dos metais é relativamente semelhante, com decréscimo na fração $\mathrm{F}_{6}(<5 \mathrm{kDa})$, exceção de $\mathrm{Ni}(\mathrm{II})$ que tem maior porcentagem complexada preferencialmente nessa fração de menor tamanho molecular. De modo geral, pode-se estabelecer a seguinte ordem decrescente de complexação dos íons metálicos originalmente complexados nas diferentes frações: $F_{2}>F_{1}=F_{4}=F_{5}>F_{3}>F_{6}$.

A Figura $2 \mathrm{~b}$ mostra que nas primeiras 24 horas de contato entre os metais adicionados e a SHA, nas frações de maiores tamanhos moleculares $\left(\mathrm{F}_{1}-\mathrm{F}_{3}\right)$, há inversão nas porcentagens de complexação dos metais quando comparadas com os dados da Figura 2a (metais originalmente complexados). Entretanto, após 10 dias de complexação, Figura 2c, a distribuição de metais nas três frações de maiores tamanhos moleculares $\left(\mathrm{F}_{1-}\right.$ $\mathrm{F}_{3}$ ) volta a apresentar, características semelhantes àquelas distribuições de metais originalmente complexados pelas SHA, mostradas na Figura 2a. Rocha et al. ${ }^{27,}{ }^{28}$, estudando a labilidade relativa de espécies metálicas complexadas com SHA, sugeriram que a diminuição da labilidade em função do tempo pode ser explicada assumindo-se que, quando em contato com as SHA, inicialmente os íons metálicos são complexados preferencialmente por sítios de complexação mais externos, portanto, mais acessíveis. Entretanto, com o passar do tempo, o complexo metal-SHA tende a se estabilizar ocorrendo rearranjos inter e/ou intramoleculares, com a transferência do metal para os sítios de complexação mais internos das macromoléculas húmicas. Assim, a espécie metal-SHA tem sua labilidade relativa reduzida em função do tempo e, consequentemente, o íon metálico fica menos disponível para participar de reações no ambiente aquático. A caracterização de mudanças na distribuição de carbono das frações após adição de íons metálicos, corrobora para confirmação da hipótese da existência de rearranjos inter e/ou intramoleculares proposta recentemente por Rocha et al. ${ }^{27,28}$.

A Tabela 3 lista as ordens decrescentes de complexação de metais originalmente complexados pelas diferentes frações de SHA, após adição de íons metálicos com tempo de complexação de 24 horas (metal-SHA 1D) e 10 dias (metal-SHA 10D). 
Tabela 3. Ordens decrescentes de complexação de metais nas frações de substâncias húmicas aquáticas extraídas de amostras de água do Rio Negro-AM. Metais originalmente complexados (SHA), após adição de íons metálicos com tempo de complexação de 24 horas (metal-SHA 1D) e 10 dias (metal-SHA 10D). Condições: $250 \mathrm{~mL}$ SHA 1,0 mg L-1 mantida em pH 5,0; adição de Ni 0,50; $\mathrm{Cu} 0,25 ; \mathrm{Zn} \mathrm{10,0;} \mathrm{Cd} \mathrm{e} \mathrm{Pb} 2,5 \mu \mathrm{g} \mathrm{mL}^{-1}$; fracionamento utilizando o SFSUF ${ }^{19}$. Frações $\mathrm{F}_{1}:>100, \mathrm{~F}_{2}: 50-100, \mathrm{~F}_{3}: 30-50, \mathrm{~F}_{4}$ : $10-30, \mathrm{~F}_{5}: 5-10$ e $\mathrm{F}_{6}:<5 \mathrm{kDa}$.

\begin{tabular}{|c|c|c|}
\hline CONDIÇÕES EXPERIMENTAIS & METAIS & $\begin{array}{c}\text { ORDEM DECRESCENTE DE } \\
\text { COMPLEXAÇÃO NAS FRAÇÕES }\end{array}$ \\
\hline Metais originalmente complexados nas SHA & $\begin{array}{l}\text { Níquel } \\
\text { Cobre } \\
\text { Zinco } \\
\text { Cádmio } \\
\text { Chumbo }\end{array}$ & $\begin{array}{l}\mathrm{F}_{6}>\mathrm{F}_{2}>\mathrm{F}_{1}>\mathrm{F}_{5}>\mathrm{F}_{4}=\mathrm{F}_{3} \\
\mathrm{~F}_{2}>\mathrm{F}_{1}=\mathrm{F}_{4}=\mathrm{F}_{5}>\mathrm{F}_{3}>\mathrm{F}_{6} \\
\mathrm{~F}_{2}>\mathrm{F}_{4}=\mathrm{F}_{1}>\mathrm{F}_{5}=\mathrm{F}_{3}>\mathrm{F}_{6} \\
\mathrm{~F}_{2}>\mathrm{F}_{1}>\mathrm{F}_{4}>\mathrm{F}_{5}>\mathrm{F}_{3}>\mathrm{F}_{6} \\
\mathrm{~F}_{2}>\mathrm{F}_{1}>\mathrm{F}_{4}>\mathrm{F}_{3}=\mathrm{F}_{5}>\mathrm{F}_{6}\end{array}$ \\
\hline 24 horas de complexação após adição de metais & $\begin{array}{l}\text { Níquel } \\
\text { Cobre } \\
\text { Zinco } \\
\text { Cádmio } \\
\text { Chumbo }\end{array}$ & $\begin{array}{l}\mathrm{F}_{1}>\mathrm{F}_{3}>\mathrm{F}_{2}>\mathrm{F}_{5}>\mathrm{F}_{6}>\mathrm{F}_{4} \\
\mathrm{~F}_{1}>\mathrm{F}_{3}>\mathrm{F}_{2}>\mathrm{F}_{5}>\mathrm{F}_{4}>\mathrm{F}_{6} \\
\mathrm{~F}_{1}>\mathrm{F}_{3}>\mathrm{F}_{2}>\mathrm{F}_{4}>\mathrm{F}_{6}>\mathrm{F}_{5} \\
\mathrm{~F}_{1}>\mathrm{F}_{3}>\mathrm{F}_{2}>\mathrm{F}_{4}>\mathrm{F}_{5}>\mathrm{F}_{6} \\
\mathrm{~F}_{1}>\mathrm{F}_{2}>\mathrm{F}_{3}>\mathrm{F}_{4}>\mathrm{F}_{5}>\mathrm{F}_{6}\end{array}$ \\
\hline 10 dias de complexação após adição de metais & $\begin{array}{l}\text { Níquel } \\
\text { Cobre } \\
\text { Zinco } \\
\text { Cádmio } \\
\text { Chumbo }\end{array}$ & $\begin{array}{l}\mathrm{F}_{2}>\mathrm{F}_{3}>\mathrm{F}_{6}>\mathrm{F}_{1}>\mathrm{F}_{4}>\mathrm{F}_{5} \\
\mathrm{~F}_{2}>\mathrm{F}_{3}>\mathrm{F}_{1}>\mathrm{F}_{4}>\mathrm{F}_{6}>\mathrm{F}_{5} \\
\mathrm{~F}_{2}>\mathrm{F}_{3}>\mathrm{F}_{1}>\mathrm{F}_{4}>\mathrm{F}_{6}=\mathrm{F}_{5} \\
\mathrm{~F}_{2}>\mathrm{F}_{3}=\mathrm{F}_{1}>\mathrm{F}_{4}>\mathrm{F}_{6}=\mathrm{F}_{5} \\
\mathrm{~F}_{2}>\mathrm{F}_{1}>\mathrm{F}_{3}>\mathrm{F}_{4}>\mathrm{F}_{5}=\mathrm{F}_{6}\end{array}$ \\
\hline
\end{tabular}

\section{CONCLUSÕES}

O fracionamento de substâncias húmicas com base no tamanho molecular, utilizando sistema de ultrafiltração sequencial com filtros de membrana é, em princípio, uma importante técnica para estudar essa complexa mistura de macromoléculas. Neste trabalho, o fracionamento possibilitou separar e concentrar as SHA extraídas de amostras de águas coletadas no Rio Negro-AM em seis frações com diferentes tamanhos moleculares: Frações $\mathrm{F}_{1}:>100, \mathrm{~F}_{2}:$ 50-100, $\mathrm{F}_{3}: 30-50, \mathrm{~F}_{4}: 10-30$, $\mathrm{F}_{5}: 5-10$ e $\mathrm{F}_{6}:<5$ kDalton. Experimentos de complexação de íons metálicos com SHA em função do tempo, mostraram que durante as primeiras 24 horas de contato, a distribuição de carbono foi alterada em todas as frações, caracterizando-se uma ordem intermediária de distribuição de carbono: $F_{3}>F_{1}>F_{6}>F_{5}=F_{2}$ $>\mathrm{F}_{4}$. Entretanto, após 10 dias de contato, caracterizou-se uma ordem decrescente de distribuição de carbono semelhante àquela estabelecida para a SHA sem adição de metais, ou seja $F_{6}>F_{2}>$ $\mathrm{F}_{3}>\mathrm{F}_{1}>\mathrm{F}_{4}>\mathrm{F}_{5}$. A maior porcentagem dos íons metálicos originalmente presentes nas SHA está complexada na fração $\mathrm{F}_{2}$, a qual tem tamanho molecular médio entre 50-100 kDa. Nas demais frações a porcentagem de distribuição dos metais é relativamente semelhante, com decréscimo na fração $F_{6}(<5 \mathrm{kDa})$. De modo geral, pode-se estabelecer a seguinte ordem decrescente de complexação dos íons metálicos originalmente complexados nas frações: $F_{2} \gg F_{1}=F_{4}=F_{5}>F_{3}>F_{6}$. Também, verificou-se em função do tempo de complexação, modificações nas porcentagens de complexação dos metais dentre as frações. Entretanto, após 10 dias de complexação, a distribuição de metais nas três frações de maiores tamanhos moleculares $\left(\mathrm{F}_{1}-\mathrm{F}_{3}\right)$ apresentou, características semelhantes àquelas distribuições de metais originalmente complexados pelas SHA. Estes resultados reforçam a hipótese de que, quando as macromoléculas húmicas interagem com íons metálicos formando diferentes espécies, devido a rearranjos inter e/ou intramoleculares, o complexo metal-SHA tende a se estabilizar em função do tempo e, consequentemente, a labilidade relativa dos íons metálicos diminui.

Assim, em águas com elevada concentração de matéria orgânica como as do Rio Negro, as substâncias húmicas aquáticas podem agir como "um tampão", diminuindo a disponibilidade de íons metálicos para participar de outras reações no ambiente aquático.

\section{AGRADECIMENTOS}

Os autores agradecem à CAPES/PICD, FAPESP e CNPq.

\section{REFERÊNCIAS}

1. Aiken, G. R. In Humic substances in soil, sediment and water. Geochemistry, isolation and characterization; Aiken, G. R.; Mcknight, M. D.; Wershaw, R. L.; MacCarthy, P., Eds.; John Wiley \& Sons; New York, 1985; p 363-385.

2. Senesi, N.; Miano, T. M.; Humic substances in the global environment and applications on human health; Elsevier; Amsterdam, 1994; p 1368.

3. Prado, A. G. S.; Souza, S. M.; Silva, W. T. L.; Rezende, M. O. O.; Quim. Nova 1999, 22, 894.

4. Rosa, A. H.; Rocha, J. C.; Furlan, M.; Quim. Nova 2000, $23,472$.

5. Thurman, E. M.; Malcolm, R. L.; Environ. Sci. Techn. 1981, 15, 463.

6. Senesi, N.; In Organic substances in soil and water: natural constituents and their influences on contaminant behaviour; Beck, A. J.; Jones, K.; Hayes. M. H. B.; Milgelgrin, U., Eds.; Royal Society of Chemistry; Cambridge, 1993; p 73-101.

7. MacCarthy, P.; Suffet, I. H.; Aquatic humic substances: influence on fate and treatment of pollutants; ACS; Washington, 1989, p 384.

8. Rocha, J. C.; De Sene, J. J.; Burba, P. Klockow; J. Braz. Chem. Soc. 1998, 9, 79.

9. Rocha, J. C.; De Sene, J. J.; Santos, A.; Toscano, I. A. S.; Zara, L. F.; J. Environ. Monit. 2000, 2, 39.

10. Walker, I.; Ciên. Hoje 1990, 11, 44.

11. Ertel, J. R.; Hedges, J. I.; Devol, A. H.; Richey, J. E.; Limmol. Oceanogr. 1986, 31, 739.

12. Sargentini Jr., É; Tese de Doutorado, Instituto de Química de Araraquara, UNESP, Araraquara, SP, 1999.

13. Malcolm, R.; Thurman, E. M. In Aquatic and terrestrial humic materials. Christman, R. F.; Gjessing, E. T., Eds.; An Arbor Science; An Arbor, 1995, p 1.

14. Town, R. M.; Powell, H. K. J.; Anal. Chim. Acta 1992, $256,81$.

15. Campanella, L.; Petronio, B. M.; Braguglia, C.; Internat. J. Anal. Chem. 1994, 60, 49. 
16. Pitombo, R. N. M.; Ciên. Cultura 1989, 41, 427.

17. Griffith, S. M.; Schnitzer, M.; Soil Sci. Amer. Proc. 1975, $39,861$.

18. Rocha, J. C.; Sargentini Jr., É; Toscano, I. A. S.; Rosa, A. H.; Burba, P.; J. Braz.Chem.Soc. 1999, 10, 169.

19. Rocha, J. C.; Zara, L. F.; Rosa, A. H.; Sargentini Jr., É; Burba, P.; Quim. Nova 2000, 23, 410.

20. Huffman, E. W. D. Jr.; Stuber, H. A. In Humic substances in soil, sediment and water. Geochemistry, isolation and characterization. Aiken, G. R.; Mcknight, M. D.; Wershaw, R. L.; MacCarthy, P., Eds.; John Wiley \& Sons; New York, 1985; p 433-451.

21. Leenheer, J. A.; Acta Amazônica 1980, 10, 513.

22. Steelink, C. In Humic substanes in soil, sediment and water. Geochemistry, isolation and characterization. Aiken,
G. R.; Mcknight, M. D.; Wershaw, R. L.; MacCarthy, P., Eds.; John Wiley \& Sons; New York, 1985, p 457-476.

23. Traina, S. J.; Novak, J.; Smeck, N. E.; J. Environ. Qual. 1990, 19, 151

24. Swift, R. S. In Methods of soil analysis: chemical methods. Sparks, D. L., Ed.; SSSA; Maddison, 1996, p 1011-1069.

25. Burba, P.; Shkinev, V.; Spivakov, B. Y.; Fresenius J. Anal. Chem. 1995, 351, 74.

26. Burba, P.; Rocha, J. C.; Klockow, D.; Fresenius J. Anal. Chem. 1994, 349, 800.

27. Rocha, J. C.; Toscano, I. A. S.; Burba, P.; Talanta 1997, 44, 69.

28. Rocha, J. C.; Toscano, I. A. S.; Cardoso, A. A.; J. Braz. Chem. Soc. 1997, 8, 239. 